\title{
Red Blood Cell Fragility in Multiple Sclerosis
}

\author{
E. A. CASPARY,* M.SC. ; FRANCES SEWELL,* B.SC. ; E. J. FIELD,* M.D., M.S., PH.D., M.R.C.P.
}

Brit. med. F., 1967, 2, 610-611

The work of Hellem (1960) and of Gaarder, Jonsen, Laland, Hellem, and Owren (1961) has made it clear that red blood cells are a potent source of adenosine diphosphate of considerable importance in determining the adhesiveness of platelets in vitro. Caspary (1965) showed that the presence of even $2 \%$ haematocrit red cells was enough to confer a normal degree of stickiness on platelets suspended in plasma. The implication of this finding, brought out in correspondence which followed the publication of the latter paper (Caspary, 1966), is that platelet stickiness might depend in some measure on the readiness with which erythrocytes yield adenosine diphosphate, and a similar suggestion has more recently been made by Harrison and Mitchell (1966) and Hampton and Mitchell (1966). Attention had been drawn to abnormality in size of red blood cells in multiple sclerosis by Plum and Fog (1959), and the present work indicates that they are also more osmotically fragile.

\section{Materiai and Methods}

Only patients diagnosed as "certain" multiple sclerosis in Professor Henry Miller's clinic have been used, together with a number referred from the regional neurological centre by Drs. John Walton and J. B. Foster. About half the patients were receiving miscellaneous drugs, mostly tranquillizers, and many were drawn from an Atromid (clofibrate + androsterone) doubleblind trial in progress. Control subjects matched for age and sex were obtained from laboratory staff and colleagues. Altogether 73 patients with multiple sclerosis (25 male, 48 female) aged 18 to 57 years were examined along with 38 normal healthy subjects ( 22 male, 16 female) aged 20 to 63 .

Blood was taken by clean venepuncture into sequestrene (at a final concentration of $4 \mathrm{mM}$ ) and tests were carried out as soon as possible-always within half an hour. No significant change in fragility was in fact noted over four hours, and the standard error of replicate determinations was 0.004 . The method used was essentially that of Parpart, Lorenz, Parpart, Gregg, and Chase (1947), the $\mathrm{pH}$ being carefully maintained at 7.4. Blood to the amount of $0.02 \mathrm{ml}$. was added to each of a series of tubes containing $3 \mathrm{ml}$. of buffered saline at the following dilutions : $0.500 \%, 0.475 \%, 0.450 \%, 0.425 \%, 0.400 \%, 0.375 \%$, and distilled water. After mixing, the tubes were left undisturbed at room temperature (c. $20^{\circ}$ C.) for 45 minutes, when the erythrocytes were spun off at 1,500 r.p.m. $(450 \mathrm{~g})$ for five minutes. The optical density of supernates was recorded spectrophotometrically at $540 \mathrm{~m} \mu$, and haemolysis determined as a percentage of the $100 \%$ reading shown by the distilledwater tube. Percentage haemolysis was plotted against buffer concentration and the $50 \%$ haemolysis point determined from the graph. All experiments were carried out without knowledge of the source of the blood and accompanied in every case by a haemoglobin estimation at the same time.

Preliminary experiments showed that minor differences in buffered saline (even though it had been made up in an apparently similar way) might lead to differences in results-all estimations being either raised or lowered. A master solution

- Medical Research Council Demyelinating Diseases Research Unit, Royal Victoria Infirmary and University of Newcastle upon Tyne, Newcastle upon Tyne 2 . was therefore prepared and stored at $+4^{\circ} \mathrm{C}$. for use in all experiments. As a further check, blood from one subject (E. A. C.) was included in all tests as a "marker" to ensure that results were consistent in general level.

\section{Results}

The results expressed as the concentration of saline producing $50 \%$ lysis are summarized in the Table. Atromid in no way altered osmotic fragility. Thus 24 patients on the drug showed $50 \%$ haemolysis with $0.447 \%$ saline, while 23 receiving placebo showed similar haemolysis with $0.448 \%$ saline. The administration of miscellaneous drugs (mentioned above) likewise did not produce any noticeable effect upon fragility. These patients were therefore regarded as a single group for further analysis. No difference was remarked in patients receiving tranquillizers or other drugs as compared with those without. Patients were regarded as in an "active" phase of the disease when a new symptom or sign had appeared during the preceding four months; doubtful deterioration was classed as "quiescent."

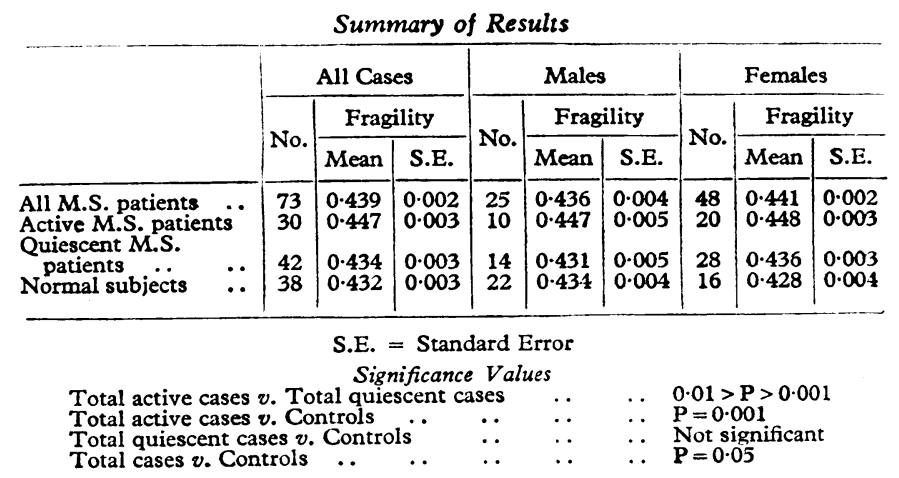

When all patients (in both active and quiescent stages of the disease) were grouped, their red cells appeared more fragile than those of controls, though the significance is doubtfully acceptable $(P=0.05)$, since there is one chance in twenty that the observed results might be fortuitous and not based on real differences. Further analysis in which multiple sclerosis patients were divided into active-that is, exacerbation within the last four months-and quiescent showed that active cases had more fragile cells than inactive ones $(0.01>P>0.001)$. Quiescent cases had no more fragile cells than controls $(P=$ 0.9 ), but with active cases of multiple sclerosis the difference from normal was highly significant $(P=0.001)$. When active and quiescent cases were split into male and female groups the numbers in each category naturally became small. Even here, however, differences approached acceptable significance. Thus when 10 male patients with exacerbations were compared with 14 quiescent males $0.05>\mathrm{P}>0.02$; for females 20 exacerbations compared with 28 quiescent subjects, $\mathrm{P}=0.01$.

Examination of the haemoglobin levels of acute and quiescent cases showed no difference between them, the average for the male patients being $14.3 \mathrm{~g} . / 100 \mathrm{ml}$. for active cases and $14.9 \mathrm{~g}$./ $100 \mathrm{ml}$. for quiescent ones. For female patients haemoglobin values were $12.5 \mathrm{~g} . / 100 \mathrm{ml}$. for active cases and $12.6 \mathrm{~g} . / 100 \mathrm{ml}$. 
for quiescent ones. Thus no significant anaemia was present in the patients examined.

\section{Discussion}

Two recent reports on the osmotic fragility of red blood cells in multiple sclerosis have appeared. Laszlo (1964) used the present method, and from a careful examination of 59 patients and 21 control subjects concluded that a highly significant increase in osmotic fragility of red blood corpuscles occurred in patients with multiple sclerosis. At the time of estimation the majority of patients did not appear to be in an active state of the disease, but unfortunately Laszlo gives no further analysis along these lines. Ketelaer and Delmotte (1966), in a very brief communication, concluded that no change in the osmotic fragility of red cells occurred in patients with multiple sclerosis.

The present findings support and extend the report by Laszlo, though their significance is far from clear. It might well be that increased osmotic fragility of red cells is a concomitant of multiple sclerosis without pathogenetic significance, and in some way a secondary effect of the condition. On the other hand, it is interesting to view it in the light of the suggestion made by Field and Caspary (1964) that platelet agglutination (perhaps of a transient nature) might occlude small veins within the nervous system and lead to reversible or irreversible changes, depending on degree and duration of obstruction. Such agglutination may result from an antigen-antibody reaction, and is accompanied by serotonin release (Humphrey and Jaques, 1955 ; Caspary and Field, 1967). The highly complex question of platelet stickiness and the factors which influence it might therefore become of importance in the pathogenesis of multiple sclerosis.

It has been established that some factor derived from red blood cells is of considerable importance in determining platelet stickiness (Hellem, 1960), and this factor is now known to be adenosine diphosphate (Gaarder et al., 1961), which can readily be liberated from erythrocytes. Caspary (1965) showed that the adenosine diphosphate resulting from the red cells represented by a haematocrit of as little as $2 \%$ could confer full stickiness upon platelets suspended in plasma. The ease with which adenosine disphosphate might be liberated from erythrocytes raises the possibility that varying properties of the latter cells might bring about differences in platelet stickiness (Caspary, 1966 ; Harrison and Mitchell, 1966 ; Bray, 1966). In particular the increased platelet adhesiveness (to glass) in multiple sclerosis, now confirmed by several workers (Nathanson and Savitsky, 1952 ; Caspary, Prineas, Miller, and Field, 1965 ; Wright, Thompson, and Zilkha, 1965 ; and others), might be referable to a primary alteration in the red cell which provides an extra rich source of adenosine diphosphate.
There are in fact some indications that red cells do show unusual properties in multiple sclerosis. Thus Plum and Fog (1959) concluded from carefully controlled direct measurement that red blood cells in multiple sclerosis were significantly larger than normal, and that bone marrow from such patients behaved differently from normal in tissue culture. They measured the area of at least 200 erythrocytes in photographs of blood films taken at a magnification of 1,400 to 1,900 diameters. They also calculated the "radius" of the red cells by measuring the circumference and dividing by $2 \pi$. They did not comment on any degree of elliptocytosis, and none has been noted in routine blood smears done in the course of the present work, though accurate measurements have not been made. Neither these observations nor the sludging of red cells in acute multiple sclerosis described by Roizin, Abell, and Winn (1953) has yet been independently confirmed.

\section{Summary}

The red blood cells of cases of multiple sclerosis are more osmotically fragile during the acute phase of the disease than when it is quiescent. Even in the quiescent phase they are more fragile than cells from normal control subjects. The significance of this finding is briefly discussed.

We would like to thank Dr. John Prineas, who made the clinical assessments in the course of the clofibrate trial from which the majority of patients were drawn; Dr. Paul Millac, who kindly made assessments of patients outside the trial ; and Professor Henry Miller, Dr. J. N. Walton, and Dr. J. B. Foster for their helpful co-operation.

\section{REFERENCES}

Bray, C. L. (1966). Proc. roy. Soc. Med., 59, 487.

Caspary, E. A. (1965), Lancet, 2, 1273. (1966). Ibid., i, 91.

and Field, E.'J.'(1967). Disch. Z. Nervenheilk., 190, 267.

- Prineas, J., Miller, H., and Field, E. J. (1965). Lancet, 2, 1108

Field, E. J., and Caspary, E. A. (1964). Ibid, 2, 876.

Gaarder, A., Jonsen, J., Laland, S., Hellem, A., and Owren, P. A. (1961) Nature (Lond.), 192, 531 .

Hampton, J. R., and Mitchell, J. R. A. (1966). Lancet, 2, 764.

Harrison, M. J. G., and Mitcheli, J. R. A. (1966). Ibid., 2, 1163.

Hellem, A. J. (1960). The Adhesiveness of Human Blood Platelets in Vitro. Oslo.

Humphrey, J. H., and Jaques, R. (1955). F. Physiol. (Lond.), 128, 9.

Ketelaer, C. J., and Delmotte, P. (1966). Brux.-méd., 46, 20.

Laszlo, S. (1964). Acta neurol. belg., 64, 529.

Nathanson, M., and Savitsky, J. P. (1952). Bull. N.Y. Acad. Med. 28, 462 .

Parpart, A. K., Lorenz, P. B., Parpart, E. R., Gregg, J. R., and Chase, A. M. (1947). F. clin. Invest., 26, 636.

Plum, C. M., and Fog, T. (1959). Acta psychiat. scand., 34, Suppl.

Roizin, L., Abell, R. C., and Winn, J. (1953). Neurology (Minneap.), 3, 250 .

Wright, H. P., Thompson, R. H. S., and Zilkha, K. J. (1965). Lancet, 2, 1109 . 